\title{
Tradición oral y memoria colectiva indígena (indigenista) en Nuestra comunidad indígena ${ }^{I}$
}

\author{
Gonzalo Espino RelucÉ \\ Departamento Académico de Literatura
}

"¿Qué de malo había en la comunidad?"

Chauqui, indio de la sierra norte ${ }^{2}$

$\mathbb{V}$ uestra comunidad indígena $(\mathrm{NCI})^{3}$ pertenece a ese grupo de textos que 1V transita entre la escritura modernista canónica y la escritura decimonónica de aquello que por entonces se Hamó folklore. En esta serie discursiva podemos indagar las tensiones conflictivas de la heterogeneidad cultural del país como metáfora de la desarmonía, que en líneas gruesas se expresa como la representación escrita enfrentada a la representación oral; signatarias, a su vez, de los componentes sociales básicos del país, y que se traduciría en la tensa relación que podemos indagar entre la "ciudad letrada" y la metáfora de la choza que sugiriéramos en $1996{ }^{4}$

\section{Biblioteca de Letras}

La práctica ficcionalgde-Hal narrativi-modernista nos advierte diversos matices que incluye el tema andino (Los hijos del Sol; La venganza del cóndor y Cuentos andinos) $)^{5}$. Una de las preguntas que deseamos explotar a lo largo de este texto es precisamente qué tipo de voz es la que representa Hildebrando Castro Pozo. Al intentar explicarnos la vida en la comunidad andina, explora y

1 Esta comunicación es resultado del estudio Tradición oral y memoria colectiva indigena (indigenista) en Nuestra Comunidad Indigena (proyecto No. 303171), financiado por el Consejo Superior de Investigaciones - Instituto de Investigaciones Humanísticas, de la Universidad Nacional Mayor de San Marcos, durante el 2000. Compart estas reflexiones con Hildebrando Pérez Grande, Manuel Larní, Esther Espinoza y Jacobo Alva.

2 Ciro Alegria, El mundo es ancho y ajeno, cap. I.

${ }^{3}$ Para el debate académico este trabajo fue presentado en tres momentos: una discusión pública, en la Escuela de Literatura sobre proyecto indigenista o indigena de Castro Pozo y dos fueron presentadas en la Escuela Andina de Post Grado, con los títulos de "La comunidad indigena: exploración modélica (Marx y Bourdieu)" y "Sujeto solidario, comunidad indigena e indigenismo" en julio-setiembre 2000.

"Espino Reluce, Gonzalo. Adolfo Vienrich: La otra literatura peruana (Lima, UNMSM, 1996); pp. 154-164.

s Cf. Espino Reluce, Gonzalo. "La representación literaria del texto oral. 'Las tres Jirkas": comunidad andina/ ciudad letrada" en Pensamiento y Escrifura N6, Lima, diciembre 2000, pp. 55-72. 
fija las diversas voces que constituyen la memoria y tradición oral de varios pueblos andinos, siendo un texto que representa un discurso de la solidaridad. Planteamos el siguiente enunciado para desarrollar nuestro trabajo:

La voz indígena que se fija en el texto pasa por el filtro de una voz "autorizada" que la inscribe en la escritura, por lo que conviene preguntarnos ¿cómo es esa voz? Esta voz, al pasar por la mediación de una voz "autorizada", proyecta o desarrolla las percepciones indigenas o, más bien propone una lectura interpretativa sobre las misma, la que, de otro lado, llega al auditorio o al público lector.

De manera que son tres tensiones las que examinará nuestro estudio: la naturaleza de la relación dialéctica entre "narrador oral" y "narrador escritural" para el signo gráfico; el contrapunto entre la memoria colectiva y la tradición oral en dos colectividades andinas, una del norte y la otra de la sierra central; y, la condición "indígena" de la voz que se fija y su correspondencia (o no) con la posición de un narrador solidario, indigenista". Estas tensiones constituyen los componentes básicos de la lectura actuai del problema oralidad/ escritura en el área andina y que inicialmente lo podemos observar en el texto objeto de estudio.

\section{Voz indígena y enumiácjólloteca de Letras}

Nuestro trabajo se ubre dentro de una tradicion renovadora que intenta proponer lecturas que allanen un nuevo episteme para la literatura peruana. Deseamos acercarnos a discursos no canónicos para explorar cómo se ha imaginado al indio y su cultura. Esto último nos interesa en tanto registro o fijación de la voz indígena en la letra impresa. Entiendo por voz indígena a la representación y a la configuración del imaginario indígena en el espacio de la ciudad letrada. Esta voz puede ser directa o mediada, puede ser solidaria o recusadora. Las actuaciones en el espacio de la escritura pueden advertirse, en la producción de diversos discursos en torno al tema del indio, que en general, conoceremos como literatura indigenista. Para efectos de este estudio propongo ampliar el corpus más allá de la producción propiamente literaria, para acudir a otros tipos de discursos, como la producción política, social - la jurídica, en el sentido que se planteó para el debate sobre la cuestión indígena: "El 'indigenismo' de nuestra literatura actual no está desconectado de los demás elementos nuevos de esta hora. Por el contrario, se encuentra 
articulado con ellos. El problema indígena, tan presente en la política, la economía y la sociología no puede estar ausente de la literatura y del arte." (Mariátegui 1927: 328).

Lo que equivale a sostener que la ampliación del corpus se justifica en tanto el tema del indio no es patrimonio privativo de la literatura como acto creativo o como testimonio de una época. Pero el hecho de que se amplíen los discursos en torno al indio pone en discusión la representación de esta voz y al sujeto de la enunciación. Precisamente, porque alrededor de la voz indígena el sujeto de la enunciación establece diversos tipos de relaciones: entre estas, aquellas donde la voz aparece de manera superficial y su presencia obedece a una operación que busca anularla o al hacerlo, construye un puente simbólico dotado de la audacia de la solidaridad, o ésta, podría más bien remitirnos a enunciados que han devenido en representación de sujetos indigenizados o, mejor aún, la presencia letrada de los indígenas.

La producción discursiva del indigenismo corresponde a lo que Antonio Cornejo Polar llamó literaturas heterogéneas (Cornejo Polar 1980: cap. I). Sin embargo, la precisión que tendríamos que desarrollar es la referida al sujeto de la enunciación. La identificación del sujeto enunciador, permitirá establecer cómo se producen los nexos de solidaridad (o no) y cómo se elaboran las mediaciones entre la cultura indígena y la cultura letrada. Es José Carlos Mariátegui quien plantea inicialmente este asunto:eca de Letras

Y la mayor mjusticia en que podria incuirir un crítico, sería cualquier apresurada condena de la literatura indigenista por su falta de autoctonismo integral o la presencia, más o menos acusada en sus obras, de elementos de artificio en la interpretación y en la expresión. La literatura indigenista no puede darnos una versión rigurosamente verista del indio. Tiene que idealizarlo y estilizarlo. Tampoco puede darnos su propia ánima. Es todavía una literatura de mestizos. Por eso se llama indigenista y no indígena. Una literatura indígena, si debe venir; vendrá a su tiempo. Cuando los propios indios estén en grado de producirla. (Mariátegui 1927: 335; énfasis mío)

Interesa la propuesta de Mariátegui porque postula una distinción epistémica con relación a esta literatura, distingue dos elementos: quiénes la producen y cómo esa literatura representa la cuestión del indio. Sobre lo primero, sostiene que esta literatura está escrita por mestizos (no indios), siendo así, la 
voz del indio será tomada por un escritor para ser representada en su escritura. La radicalidad de esta propuesta reside en la ausencia del indígena como portador de su propia escritura. ${ }^{6} \mathrm{La}$ literatura indigenista no es una literatura de indios, sino realización de sujetos extraños, ajenos a la comunidad, constituye un discurso de la ciudad letrada, no de la choza. Los límites de estas realizaciones estarán dadas por la mediación ejercida, por la capacidad o no, de que la voz indígena aparezca con nitidez y transparencia, capaz de revelar la situación del indio (verismo) y una voz competente para hacer visible la cultura indígena (percibir el ánima del indio).

Se trata pues de un tipo de literatura donde el sujeto de la enunciación resulta un problema en tanto se constituye en mediador. No siempre podemos esperar que esté procesando dicha producción de manera nítida y transparente, de allí el "artificio en la interpretación y en la expresión". En la medida que la mediación establezca lazos de solidaridad con el referente, la distancia se aminorará y dejará fluir la voz indígena. En términos metodológicos, tendríamos que observar una primera diferencia en el sujeto de enunciación y la constitución de ese sujeto en el terreno de sus propios enunciados, es decir, hay que distinguir, si es un sujeto indígena el que se expresa en estos textos o si es más bien un sujeto letrado que asume la voz del indio o si este sujeto, al querer representar la voz del indígena, más bien se convierte en yentrílocuo.

Me interesa, de unjado, detenerme enda constitución del autor en sujeto solidario desde el relato. Este proceso.lo revisaré en relación con las imágenes que sobre la comunidad indigena ofrece en su relato. Distingo al sujeto autoral del sujeto social que al convertirse en portador de un signo no desarrolla equivalencias unívocas tales como la autor = narrador, al contrario, postulo la distinción entre el sujeto civil y el sujeto del relato: el "nombre propio, se instituye como una identidad social constante y durable que garantiza la identidad del individuo biológico - dice Pierre Bourdieu- en todos los campos posibles donde interviene en calidad de agente, es decir en todas sus historias de vida posibles" (1998: 10), de allí, la necesidad de reconocer una dialéctica del autor como sujeto civil y de lo que este mismo sujeto puede realizar en términos discursivos, es decir, como narrador. Para el caso que estamos estudiando, se produce esa doble dialéctica, un sujeto civil que socialmente adhiere una postura

\footnotetext{
${ }^{6}$ Lo cierto, es que, para la época de Castro Pozo y Mariátegui, el asunto de la relación entre escritura y oralidad no era un tema emergente. De manera que las culturas se consideraban desarrolladas si estas habían accedido a la escritura. Esto explica los límites del grafocentrismo de Mariátegui.
} 
solidaria frente a la cuestión indígena y sujeto discursivo que elabora un texto que se instala como portavoz del indígena para el solar. Lo que equivale a decir que Castro Pozo, inscribe y elabora, en términos discursivos, un relato solidario que lo emparenta al indigenismo de las primeras décadas del siglo XX. ${ }^{7}$

Hildebrando Castro Pozo es un desclasado que renuncia tempranamente a su condición mesocrática para adherir muy pronto las posiciones socialistas de los años $20 .{ }^{8}$ Se encuentra en la disyuntiva de asumir una experiencia que le permite conocer el mundo indígena en su condición de letrado (maestro de escuela primero, luego abogado) en un contexto donde la efervescencia indianista era promovida por el gobierno; desde la perspectiva de los indigenistas, reconoce la necesidad de la denuncia para restituir los derechos indígenas y su necesaria inclusión en la nación y cuando no, fuente que inspira nuestra identidad (Cf. Burga, Galindo, Kapsoli). La voz del joven abogado sirve entonces para denunciar el estado de la comunidad, ya no como hecho decorativo, sino como parte de la sociedad peruana, por eso, el texto, en sí mismo es un discurso de denuncia y un testimonio de la yoz indígena inscrita por un sujeto solidario.

\section{2. ¿Indios humanos?}

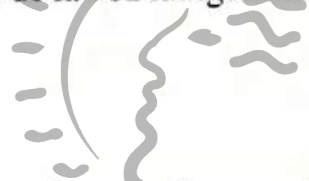

En ese estado de cosas cabe recordar que el conocimiento de los indígenas peruanos, pasaba, primero por desentrañăr choy, diríamos desestructurarun discurso ideológico que fue promovido y reiterado por los patricios de la República, el mismo que presentaba al indio como sujeto descalificado para el progreso y en el extremo de la ciudad letrada, la aristocracia hispana e hispanófila, concluía el viejo debate indiano sobre la naturaleza del indio al definirlo como lo hiciera Sebastián Lorente: "yacen en la ignorancia, son cobardes, indolentes, incapaces de reconocer los beneficios sin entrañas, holgazanes, rateros, sin respeto por la verdad y sin ningún sentimiento elevado, vegetan en la miseria y en las preocupaciones, viven en la embriaguez y duermen en la lascivia". Este argumento constituye una pauta ideológica que pone en duda la

\footnotetext{
7 Dora Mayer lo reconoce como uno de "Los próceres del indigenismo" (1946: 414).

"Sobre su condición de desclasado ver: Montoya, Rodrigo, "Prólogo a la segunda edición", Nuestra comunidad indigena, pp. X-XI. La revista Folklore $\mathrm{N}^{\circ} 16$ (1946) le dedica un homenaje póstumo a Hildebrando Castro Pozo. Sobre la vida del autor, véase los textos de Amadeo Rivera, Nicanor de la Fuente, Dora Mayer y Luis E. Valcárcel; sobre valoraciones de su obra, véase los trabajos de Florencio de la Sierra, José Varallanos, Juan María Merino. Erasmo Roca S. y Mario Vargas Llosa; y, sobre su condición de maestro, ver los artículos de José S. Warner, Pablo M. Uceda, Graciela de Urteaga y Anaximandro Vega.
} 
condición humana del indio. La consecuencia será postular el exterminio de ia raza india. Para el XIX y las primeras décadas del XX se produce una reconversión discursiva de esa modernidad que terminó confiando en las ventajas positivista de la ciencia; ésta se traduce en la mezcla de las razas, tal como la sugerían hacia fines del XIX los jóvenes Francisco García Calderón y Clemente Palma. El primero había señalado que la Colonia defendió los derechos de los indios, que la República había destruido todos los mecanismos de protección que éstos tenían. Si este era el argumento, entonces, la ideología del progreso se impone por la vía positivista: o se trata de civilizar a los indios, es decir, que el indio se incorpore a la cultura del blanco; o, se produce la mez-cla racial, postulado derivado de los fundamentos biologistas. Es Clemente Palma quien sostiene en su tesis de Bachiller en Letras, El porvenir de las razas (1896), que la raza india ocupa la escala más baja del desarrollo humano:

La india, raza inferior, sorprendida en los albores de su vida intelectual por la conquista; raza que representaba probablemente la ancianidad de las razas orientales; que era, por decirlo así. el deshecho de las civilizaciones antiquísimas, que pugnaban por reflorecer nuevamente en un ricorsi lento y en energía, propio de una decrepitud conducida inconsciente en las venas. (Palma 1999: 230)

Signada por la inferioridad, la ancianidad y la decrepitud, la raza indígena queda inhabilita para cualquier desarrollo ulterior $o$, mejor aún, aparece como obstáculo para el progrésodecemonónico. Anteestá imposibilidad, Palma postula en su tesis la mezcla racial:

En mi humilde concepto, creo -dice Clemente Palma- que él puede dárselo la raza alemana. El alemán es físicamente fuerte: vigorizará los músculos y la sangre de nuestra raza: es intelectual, profundamente intelectual: dará solidez a la vida mental de nuestra raza, armonizará, en el cerebro de los escogidos el sentimiento artístico, herencia de la raza latina, con el espíritu científico de los germanos; es sereno, enérgico, tenaz, será contrapeso a la vehemencia, debilidad e inconsistencia de los criollos

[...]

Pero, ¿qué importa que este concepto sea poco poético, si él es la fórmula de la felicidad y superioridad futura del Perú?

¡Oh!, señores, nada más prosaico que el Progreso. (Palma 1999: 231) 
Esto respecto al problema a la propuesta biologista. ${ }^{9}$ Sin embargo, después de la Guerra del Pacífico hay un nuevo orden de percepciones que enfrenta estas posturas y retoma el argumento civilizador de la raza. Pero al hacerlo se ve presionada por lo que ocurre en el entorno social, reconoce que el problema es la ausencia de este segmento social en el tejido oficial de la sociedad peruana. Manuel González Prada resume tales posiciones a fines del XIX y comienzos del $\mathrm{XX}$, pensar la nación peruana como homogénea e integrada, nos lleva a dos problema en el discurso pradiano, si la solución no es entonces la mezcla racial entonces el camino elegido será la educación. ${ }^{10}$ Pero la ineficacia de esta propuesta, lleva a don Manuel a insistir:

Nada cambia más pronto ni más radicalmente la psicología del hombre que la propiedad: al sacudir la esclavitud del vientre, crece en cien palmos. Con sólo adquirir, el individuo asciende algunos peldaños en la escala social, porque las clases se reducen a grupos clasificados por el monto de la riqueza. A la inversa del globo aerostático, sube más el que más pesa. Al que diga la escuela, respóndasele: la escuela y el pan.

La cuestión del indio más que pédagógica, es económica, es social.

(González Prada 1975: 131; énfasis mío).

José Carlos Mariátegui heredero de la propuesta pradiana la radicalizará. La cuestión del indio no es un problema sólo de sensibilidad sino -y fundamentalmente- un problema sojcial. El problema de datierra a partir de la cual se consolida la noción de culfura Puccinelli Converso»

\section{Comunidad: espacio de la cultura}

Estamos definiendo a la comunidad como el espacio de la cultura, es decir, como el lugar donde se realiza la convivencia y se produce, para una vida exitosa, un conjunto de artefactos e imaginarios que la hacen posible. Las comunidades "reposan sobre las bases de la propiedad en común de las tierras en que viven y cultivan o conservan para pastos y los lazos de consanguinidad

\footnotetext{
- Recuérdese que las investigaciones sobre el genoma humano han definido, en la práctica, la no existencia de las razas. El debate sobre este aspecto tuvo lugar desde 1999 y en febrero de 2001, las transnacionales y los Estados entraron en franca competencia por lo que dieron a conocer sus resultados: La diferencia entre los seres humanos es de $0.05 \%$, somos iguales en $99.95 \%$.

${ }^{10} \mathrm{Cf}$. "Discurso en el Politema" (1888) en Pájinas libres.

"Cf. "El Problema del Indio", 7 ensayos de interpretación de la realidad peruana.
} 
que unen entre sí las diversas familias que forman el ayllu." (NCI 16) Lo que equivale a postular que las comunidades indígenas se asientan sobre un territorio, y es en ese espacio donde se organiza la vida. Conviene a efecto de esta investigación añadir dos elementos que cruza la idea de comunidad: la primera, asumida por el autor, se refiere a los contextos vividos por los indígenas y la posesión de la tierra. Si la imaginamos como república de indios éstas socialmente han sido acorraladas por la república de blancos, más exacto será decir que fueron siempre saqueados y los comuneros desalojados de sus tierras. La segunda, tiene que ver con esas imágenes bucólicas, estacionarias, sin cambios ni transformaciones en el tiempo. Entendemos a la comunidad indígena como una estructura social que vive en el tiempo, por eso mismo, la comprendemos como entidades también en proceso de cambio, tal como advirtió el antropólogo José María Arguedas. ${ }^{12}$

La militancia indigenista de narrador solidario traduce su entendimiento de la comunidad como lugar específico de desarrollo de una cultura, las mismas que, según nuestro narrador, inspira sentimientos admiración y socialmente estaría "enseñando" a la ciudad letrada una probable moral. Y es ese peculiar "modo de ser" lo que la unifica y da cohesión a la comunidad indígena; imaginario que permite que el ayllu perviva. No precisamente por ser estático o residual, sino porque contribuye con explicaciones y estructura su universo. Por eso dirá el narrador:

\section{Biblioteca de Letras}

He procurado agrupar ep los acápites anteriores los datos concernientes a las supervivencias, supersticiones y leyendas de carácter religioso que actualmente integran la conciencia moral de estos pueblos y que, en la mayoría de los casos constituyen la causa fundamental de sus decisiones y peculiar modo de ser. (NCI 164-65)

Estos imaginarios tienen que ver con las formas como la comunidad trasmite sus sentimientos, sus anhelos y cómo configura su visión del mundo. Cada comunidad es portadora de imágenes que anclan como formatos que pertenecen a la cultura. La comunidad indígena está definida por la propiedad en común y los vínculos familiares. La posesión de dichos territorios viene "desde

\footnotetext{
12 Los trabajos de Arguedas examinan los procesos de cambio operados en las comunidades indigenas, sobre todo del Valle del Mantaro y Puquio, cf: "Cambio de la cultura en las comunidades indigenas económicamente fuertes", 1958 (Arguedas 1987:28-33), "Puquio, una cultura en proceso de cambio la religión local" (1987: 34-38) y "Evolución de las comunidades indigenas. El Valle del Mantaro y la ciudad de Huancayo: un caso de fusión de culturas no comprometidas por la acción de las instituciones de origen colonial" (: 80-147).
} 
tiempos inmemoriales", no siempre por la existencia de un documento escrito, sino por "los recuerdos de un lejano repartimiento" y "cincuenta generaciones [...] [que] se han sucedido usufructuándolas." (NCI 17) Las tierras comunales pertenecen a todo el ayllu, es decir, a "conjuntos de familias que forman la comunidad" (: 18). Socialmente la comunidad se construye como espacio donde todos comparten la centralidad del ayllu que hace posible la convivencia.

La comunidad así mismo posibilita un substrato cultural que tiene que ver con el sitio en la historia. Se trata de experiencias diseminadas a lo largo del país, pero estas están signadas por vínculos de tradición, es decir, comparten un universo cultural y ritual que permite la vida exitosa en términos culturales aunque en términos materiales se pueda constatar carencias. La identidad es lo que se recrea a lo largo del texto. Tres de estas formas tienen que ver con el ayni o minga; la protección o noción de mayoría de edad (referido a la pareja, al matrimonio) y la protección a los niños huérfanos. La comunidad estructura la vida de sus miembros, por eso, no sólo constituye una experiencia colectiva. En el caso de Nuestra comunidad indigena, tiene lugar a través de la tradición oral ${ }^{13}$ que Castro Pozo fija y que a su vez representa la memoria colectiva de algunas comunidades del Perú. Entienđo por memoria colectiva a las imágenes que una colectividad se construye sobre sí y que se trasmite a través de la palabra o por medio de formas semióticas capaces de ser rememoradas en circunstancias que así amerite la ocasión. De allí la enorme importancia de la etnografía sobre los diversos rituales culturales que presenta el autor, es decir, lo que, en la vida andina se construye como identidad.

\section{"Jorge Puccinelli Converso"}

En este contexto, Castro Pozo, registra variadas manifestaciones de la cultura oral, así fija relatos y canciones de diversas zonas del país que expresan la "emotividad estética comunal". Al elaborar la imagen de la comunidad indígena el narrador allana distintos procesos culturales que viven dichas colectividades y describe la vigencia o las imágenes que se aferran como marcas de una memoria colectiva. La comunidad que propone el narrador no está imaginada como homogénea; incorpora una colectividad que escapa al ensueño romántico. No son conglomerados similares, en su interior hay tensiones. Los espacios o referencias sobre las que se conforma la comunidad no siempre es un ámbito igual, sino que difieren una de otra, sin embargo, el punto de igualación se

13 Asumo aquí la categoría tradición oral en los términos trabajados por Juan Carlos Godenzzi: "Tradición oral andina/ Problemas metodológicos del análisis del điscurso" (1994/1999) Véase también Gonzalo Espino Relucé, Literatura oral y tradicion" (Memorias $\left.\mathrm{N}^{\circ} 2,1988: 1-2\right)$ y "Tradición oral y memoria colectiva" (1999: 53-66). 
establece con relación a los derechos y obligaciones entre sus integrantes. La imagen de la comunidad indígena que el autor desarrolla asume las diferencias y las complementariedades que entre éstas se tejen.

\section{Voz indigena y testimonio}

La realización de la escritura tiene como referente la autoridad de la voz que organiza el texto. De hecho Nuestra comunidad indigena resulta una lectura de la realidad de las primeras dos décadas. Tal condición referencial se presenta en un discurso que no tiene rasgos ficcionales, sin embargo, el texto se convierte en inverosímil cuando éste se transforma en representación, en signo, es decir, no sólo permite que la voz anónima aflore, sino que al hacerlo, pasa de la función denotativa a una suerte de apego poético (Todorov) que será lo que define al relato de NCI. La representación etnográfica de esa realidad en el signo está inspirada en la función del sujeto del relato como testigo; su estatuto de verosimilitud de ésta inspira en la autoridad de la voz representada, en la elaboración del relato etnográfico y ên la compilación de los textos orales el NCI.

La voz que habla el texto define un tipo de relación que al acusar la voz indígena, ésta se traduce en la voz de un indigenista. De manera que no siempre es la voz del sujeto indígena, sino más bien del sujeto indigenista. Es decir una voz que no acepta la dominancia del sujeto de la comunidad andina sino del sujeto que se apropia de la palabra en la ciudad letrada. Esto se expresa en la metodología de recopilación que desarrolla ep narfador.' Todo esto tiene que ver a su vez con las formas como están representadas esas voces: "Esta y otras frases que están entre comillas son netamente populares y las consigno literalmente, para conservar su verdadero significación y colorido" (NCI, nota 1); lo que equivale a la instalación de un supuesto de autoridad, es legible la voz indígena en tanto el narrador notifica, ex profeso, que se trata de la voz del otro, esta voz se representa entrecomillado, se intenta ser objetivo en los términos positivistas de la época. Los textos recopilados en buena cuenta se fijan a modo de fragmentos, pues opta casi siempre, se da por sobrentendida su escritura, lo que determina la fractura del relato en el sentido de escisión, pues anula determinados fragmentos. En otras ocasiones se trata de las traducciones que realiza el autor, no siempre transcribe en la lengua nativa.

El relato etnográfico de Hildebrando Castro Pozo se sitúa en la posibilidad de organizar un discurso que está validado por la condición de un sujeto 
que no sólo está informado. No sólo conoce lo que la ciudad letrada le ofrece como acumulado, sino que, además, tiene que elaborar un paradigma de validación para aquello que indica su escritura, aunque no está exenta de los problemas sobre el manejo sistemático de las culturas indígenas en los primeros treinta años del siglo XX. Es evidente, como dice el propio Castro Pozo, para entonces

la falta absoluta de fuentes de información, ya que hasta el presente nadie se ha preocupado de estudiar estos fenómenos, he tenido que tropezar con la enorme dificultad de la reserva indígena, la multiplicidad de los dialectos del quechua y la reconstrucción paciente y sistemática de multitud de leyendas, prácticas o supervivencias que sólo he podido completar teniendo a la vista una serie de datos y observaciones personales. (NCI 164-65)

Lo que equivale admitir que los estudios sobre la comunidad para entonces eran precarios, de allí esa suerte de dispersión que los ojos del etnógrafo suministra en su relación con el universo que intenta representar. ${ }^{14}$

A la ausencia de información certera y válida, el autor apela a estrategias que tienen que ver con el acceso propig a las culturas orales indígenas ("reserva indígena") y las fronteras iđiomáticas (consus variantes dialectales), por lo que la voz autorizada demanda la consistencia de su trabajo con observaciones personales y la propuesta de un sistema que permita una lectura competente en ese sistema. Asunto que es abordađo y enfrentado básicamente a través de tres mecanismos: la observación directa del autor; la procedencia o referencia a indígenas que han informado el asunto $\delta$ tema, $y$, las comunicaciones que el narrador establece entre sujetos desu misribestatus, lo quée equivale a decir letrados. De manera que el tono de la primera persona será uno de los argumentos que fluye como autoridad para el texto: "He aquí la muestra de unas 'cumananas' oídas por mí en una chichería de la hacienda Parales, valle de Piura" (NCI 258). Esta autoridad se refrenda en las observaciones que él mismo ha realizado, en tanto testigo de parte, por lo que su autoridad proviene del hecho de ser un individuo que ha presenciado lo ocurrido en la comunidad. Observar, estar atento, preguntar o tomar apuntes implica la consignación de una información mediada por la autoridad de quien ha estado por esos lares.

Haber estado en el espacio indígena, en el territorio indio, da una autoridad en la ciudad letrada que lo legítima como palabra empoderada. No sólo tiene

14 Es obvio que el narrador de NCI está evitando cuando menos dos trabajos fundamentales que se publican en la época, me refiero a los de Adolfo Vienrich y de los esposos D'Harcourt. 
el poder, sino el saber que trasmite. Leamos a continuación algunas formas utilizadas en el relato: "He tenido oportunidad de presenciar..." (NCI 26); "Conservo anotaciones referentes a familias comunales..." (: 85); "El relato anterior fue tomado, el año 1904, en un mortuorio de la Hda. La Lágrima y casi al pie de la letra" (: 20 , nota 1 ); etcétera o esta que supone:

En Piura, Lambayeque y Huaral la credulidad indígena acepta las transformaciones del brujo en toda suerte de animales, pero en concreto no he podido especificar un solo caso, pues paulatinamente ha ido desapareciendo el 'yo vide' testifical iqueño a que acabo de referir y en donde, como se ha visto, cada individuo es una síntesis de la superstición local. (NCI 213)

La validación textual se basa en hechos observables, lo que se informa es contrastado con los hechos, por lo que debe subrayarse el carácter experimental de estos trabajos, que como metodología le da estatus científico, o si quiere, se acoge al argumento positivista.

Cuando lo que el autor anota o refiere, no es una observación suya, la autoridad proviene de quienes conocen la zona están vinculados a la vida campesina. Así es posible imaginar que la información sea autorizada por quienes viven o conocen la zona: "Este cuento me lo refirió el indígena don Pedro Meza, de San Jerónimo y casi igual don Gregorio Yupanqui, de Pacha" (NCI 217: nota 1) o "Me refieren que hay algunos que saben leer música perfectamente y han compuesto algunas plezas sagradás y ofras de diferente índole." (:168), etcétera. Esta a su đueźpedede suministrar una formà mixta. Aceptada la referencia, es corroborada por un indígena, es decir, se combina dos formas: la referencia a la segunda persona y la observación directa: "Esta leyenda me la refirió la familia Meza, del pueblo de San Gerónimo, de la provincia de Huancayo, integrante como aparece en el relato. - Un indio de Apaycanchilla también la ha oído referir a sus padres" (NCI 175, nota 1). En este caso, como se puede notar, el asunto se ve precedido por la información de una familia del lugar, pero ratificada (mejor aún, controlada), por lo que dice un indígena. Esto sucede, también en la selección que realiza, al transcribir las creencias y leyendas: "Entre los pueblos comuneros serranos la creencia popular del 'human-taccta' ha engendrado varias leyendas de las cuales consigno la siguiente" (: 215$)$, acto seguido se transcribe el relato.

Las fuentes escritas constituyen otro recurso que apela para dar sustento al discurso indigenista. Así, la historia, las cédulas reales, edictos y leyes o los 
escasos trabajos realizados sobre el tema, permiten afirmar algunas de las proposiciones del autor. El narrador acudirá a esto para validar lo que señala y por lo mismo, explicita sus fuentes. Da autoridad para expurgar lo que desea desarrollar en tanto autor. Se informa, por ejemplo, el cantor, "que canta la misa en los pueblos donde no va de común el cura", fue "creado en los pueblos indígenas por la ley VI de 8 de octubre de 1560 que ordena que 'en todos los pueblos que pasaren de cien indios, haya dos o tres cantores"' (NCI 167), etcétera.

La otra forma de organizar su discurso que asume el sujeto de la enunciación tiene que ver con la autoridad entre iguales. Es decir, entre la propia comunidad letrada, se acude a estos en calidad de sujetos conocedores y que por lo tanto son portadores de la verdad:

Mi inolvidable amigo don Julio César Casablanca, de quien tantos y tan preciosos datos he recogido, me manifestaba al respecto, que en las fiestas de San Juan y Carnavales en las punas, con ocasión del señalamiento del ganado, los bailarines hacen huecos en el sitio en que zapatean pues en aquel se la pasan horas íntegras con el 'chuto' hastalas orejas, emponchados, los brazos caídos hacia lo largo del cuerpo, la cabeza inclinada, como mirándole los pies a su compañera. (NCI 240)

Se trata de letrados que viven en los pueblos del interior no siempre en las mismas comunidades 0 , más específicamente, en las capitales de las provincias, aunque no siempre los informantes son nominados. En muchos de los casos, basta la autoridad de la vobzautoral para queda información se de por cierta.

\section{Relato etnográfico}

La cultura indígena es percibida como un universo complejo e integrado. De allí que ninguna de las formas que el autor refiere deja de vincularse a la pluralidad significativa con que son acompañados los relatos o eventos que se narra. Desde lo cotidiano se trama la forma del relato en un tejido que ubica el proceso preciso en que se produce el acto de producción simbólica. Esto es de suma importancia tal como ha analizado Bruce Manheinn $(1986,1987)$ para el caso de la canción quechua popular, al recordarnos cómo el relato del texto no se puede desprender del contexto de producción. Este contexto de producción es el que nos interesa respecto al texto. Lo que equivale a decir que entre texto y contexto se produce la generación de un documento cuyo sentido será exac- 


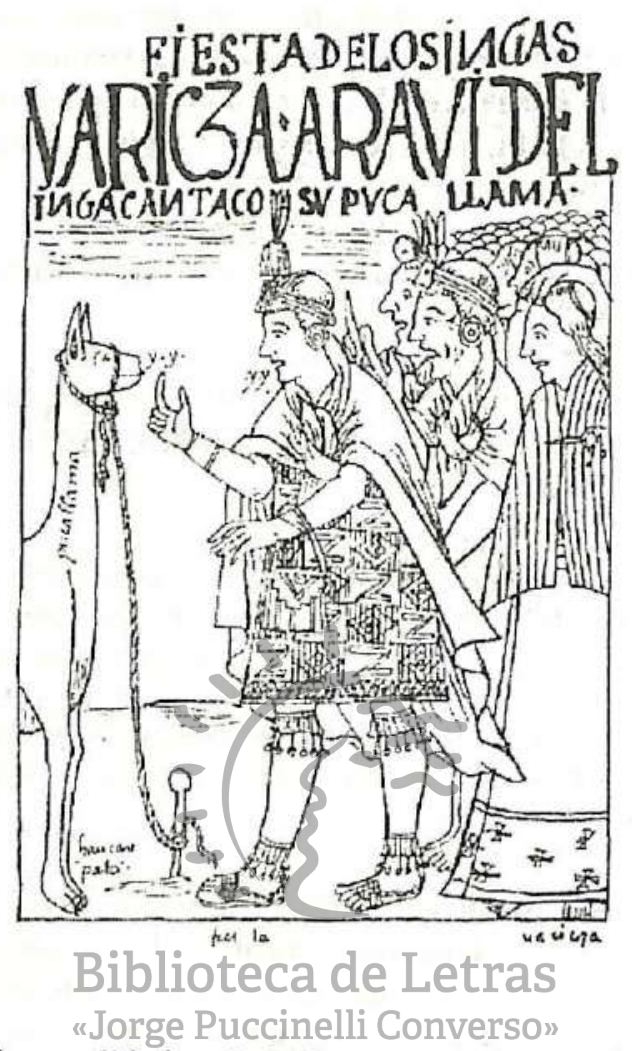

tamente ubicar las cualidades simbólicas y rituales que lo acompaña. Para esto, Manheinn se remite al análisis de un texto de Guamán Poma de Ayala. La iconografía de Guamán Poma pone de relieve dos cosas: que el texto poético no es una realización independiente, sino una relación intertextual. Y dos, que la realización textual, prehispánica tiene que ver con el ritual indígena.

En "Fiesta. Uaricza, araui del Inga"15, la ilustración es sumamente sugerente: dos elementos se distribuyen el espacio, al lado izquierdo la llama (descrita como "pucallama") y al lado derecho el inca y su séquito. La llama ha sido graficada hasta las patas delanteras, su apariencia es de vigor y está atenta; podría decirse, incluso, que alegre; el inca, con solemnidad exhibe sus mejores pren-

${ }^{15} \mathrm{Cf}$. Felipe Guamán Poma de Ayala, Nueva corónica y buen gobierno. Ed. y prólogo Franklin Pease G.Y. México, Fondo de Cultura Económica, 1993; t. 1; pp. 238, 241-242; ff. 318-321. 
das, lleva toda la indumentaria que lo califica como autoridad real, la coya que acompaña al inca ilustra también su autoridad en la falda y el corpiño. Es la llama la que asume una actitud lastimera que es repetida por el inca. Obsérvese que la letra y la boca de la llama están ligeramente más arriba del inca; la llama dice "y$y$ ", el inca repite " $y-y$ " ("con compás, muy poco a poco, media hora dice $y-y-y$, al tono del carnero, comienza el inga como el carnero dice, y esta diciendo yn."). Los rostros que acompañan al inca repiten lo dicho, se puede imaginar que el resto del séquito repite lo mismo. Luego el relato adquiere esa autoridad aludida:

Fiesta. Uaricza, araui del Inga. Las fiestas cantar y bailar, uaricza, que cantaron puca llama, al tono del carnero cantan, dice así: con compás, muy poco a poco, media hora dice $y-y-y$, al tono del carnero, comienza el inga como el carnero dice, y está diciento yn. Lleva ese tono y de allí comenzando va diciendo sus coplas, muy muchas responden las coyas y ñustas, cantan a voz alta, muy suavemente. $Y$ uaricza y araui dice así: araui araui aray araui araui yau arauti, van diciendo lo que quieren, y todos al tono de araui. Responden las mujeres: tuaricza ayay uaricza, chamay uaricza, ayay uaricza, todos van de este tono y las mujeres responden. Y el haylli: ayau haylli yau haylli, uchuyocho chacrayqui? Uchoy tunpalla samusac. Ticayoccho chacrayque? Ticay tunpalla samusac, y a este tono responden las mujeres.

Dice el hombre: chaymi coya,

responde la mujer: ahaylli

chaymi palla

ahaylli, patdlanpt ahyalti,nelli Converso "

chaymi ñusta,

ahaylli

chaymi ciclla,

ahaylli.

El araui y canción lastimosa que cantan las ñustas y los mozos tocan el pingollo, Morcotollay morcoto, llulluchallay llullucha, mana soncoyqui queuiccho? mana uacaycunqui. Cicllalay caspa, coyallay caspa, ñustallay caspa. Unoy uiquellam apariuan, yacuy parallam pusariuan, chay llicllayquita ricuy cuspa, chay acsoyquita cauay cuspa, mana man pachapas chiciancho, tuta riccchariptipas, mananatacmi pacha pacarincho. Camca, coya, camca, señora. Mananachi yuyariuanquicho? Cay sancaypi, poma, atoc, micouaptin. Cay pimaspi uichicasca, quicasca tiapi palla. ${ }^{16}$

${ }^{10}$ Guamán Poma de Ayala, op. cit., pp. 241-242. 
El relato etnográfico permite precisamente presentar el contexto en que se desenvuelve el texto como acto ritual y comunal. Desprenderlo de esa situación supone obviar las significaciones que se construyen y que dan sentido a la producción simbólica. Así el texto está contextualizado y es en ese marco que aparece. A eso llamo relato etnográfico. Se describe el evento (la situación en que tiene lugar la producción discursiva); luego, como parte de esa descripción, aparece el texto poético. Este es el sentido que deseo recuperar para el trabajo en nuestra percepción sobre relato etnográfico.

A través del relato etnográfico la voz del autor no sólo se consolida como voz indigenista sino que al optar por esa forma discursiva, permite que observemos el proceso, accedemos a textos recubiertos de su condición primigenia, la del ayllu. Así la "Pirhualla-pirhua" no sólo la canción colectiva sino que podemos recuperar su condición comunal, su ethos comunitario. El discurso poético aparece en su contexto, dentro del escenario en que se canta. La descripción recupera el valor que tiene esta letra para la comunidad, en este caso referido al matrimonio. El texto empieza preguntando sobre el impacto de la Iglesia en las relaciones de pareja, pone en cuestión si la virginidad es propia de las costumbres indígenas y advierte que ésta fue introducida por la Iglesia, como elemento propio de la pureza sexual antes del matrimonio. Para ello apela a la descripción del encierro, es decir el himmineo, luego continua la danza que realizan entre los "convidados":

Acto continuo los convidados bailan una danza voluptuosa, durante la que se pronuncia frase alusivas al estado de los encerrados y ejecutan figuras como las de nuestra cuadrilla -de espalda y de frente, todas tendiente a simbolizar el acto carnal.

El maestro de ceremonia, que por lo general es el padrino ordena en seguida que la murga comunal entone la danza "Pirhualla-pirhua" y entonces las parejas se deshacen y comienzan una especie de huayno-danza, picaresco e intencionado durante el cual, conforme lo ordena el maestro de ceremonia, deben proceder las parejas. He aquí algunas de sus estrofas:

Pirhualla, pirhua

Como se divierten,

Pirhualla, pirhua

Como vos no puedes... (NCI 101). 
Este proceso, propio del relato etnográfico, es recuperado por Hildebrando Castro Pozo y hace que la producción indígena que él pauta en su libro, se precisa en varios momentos al recurrir a este estilo de discurso. La contextualización del texto que se ofrece es lo que hace que relato se convierta en etnográfico toda vez que suspende la descripción en los términos de un señalamiento puramente interpretativo para pasar a ejecutar no sólo la interpretación sino la descripción del evento, lo que posibilita que el relato o canción esté situado por sus características de enunciación. Lo que va ocurrir es la fusión o mezcla del relato con testimonio. Se pasa de la descripción analítica al ofrecimiento de un enunciado cuyas características corresponden básicamente a la totalidad de significaciones rituales que pueden estar acompañando al texto que se presenta, esto, sin embargo no es una operación, consistente a lo largo del texto, pero alcanza relieve en varios de los enunciados precisamente por su carácter testimonial.

\section{Conclusiones}

Nuestra comunidad indigena de Hildebrando Castro Pozo resulta una de las más serias etnografías en una época en que se descalificaba a los indígenas peruanos. Asume la comunidad como espacio de realización de la vida y la cultura. Y su importancia radica en que en ésta queda consignada la memoria de la tradición oral dicha y escuchada entre fines del siglo pasado y comienzos del XX de indígenas "de carney huese"dPesde la perspectiva del narrador este es un texto que valora la comunidad indígena como fundamento de la construcción de un tejido social equitativo o como fuente de inspiración de nuestra identidad nacional. No es la imagen de inca, sino el indio real, el indio empobrecido y acorralado. El tipo de narrador que se instala en el texto es solidario, por lo mismo, se constituye en indigenista de primer orden. La tradición oral está consignada en su espacio de producción. Esta abarca diversos momentos del ciclo vital de los indígenas -de Piura y el Centro del Perú, respectivamente- y queda consignada en un tipo de relato que hemos denominado relato etnográfico. Esta forma discursiva permite adentrarnos en la performance del relato o de la producción de la tradición oral en las diversas ocasiones que el libro de Pozo los recoge. Y sugiere el estatus del sujeto de enunciación como indigenista. No es propiamente la representación de la voz del indígena sino voz mediadora que procura adentrarse en el mundo del ayllu. 


\section{BIBLIOGRAFIA}

ALBERTI, Giorgio y Enrique MAYER (Comp.)

1974

Reciprocidad e intercambio en los Andes peruanos. Lima, Instituto de Estudios Peruanos.

ALEGRÍA, Ciro

1983

El mundo es ancho y ajeno. Madrid, Alianza Editorial.

ARGUEDAS, José María

1987

Formación de una cultura nacional indoamericana. Compilación de Ángel Rama 4a. ed., México Siglo XXI, 1987.

1964.

"¿Qué es el folklore?" en Cultura y Pueblo, Lima 1964-1965.

AUGÉ, Marc

1998

Las formas del olvido. Trad. Mercedes Tricás Preckler y Germán Andújar. Barcelona, Ed. Gedisa 1998 (Les formes de l'oubli, 1998).

CASTRO POZO, Hildebrando

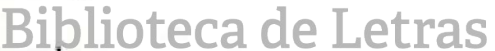

1924

Nuestra comunidad indígena. Lima.

1979

2a. ed. Lima, ed. de Hildebrando Castro Pozo C.

BOURDIEU, Pierre

2000

El sentido práctico.

2000

Alta costura y alta cultura. Trad. Ana Teresa Martínez. Cuzco, Curso de Epistemología - Escuela Andina de Postgrado 2000, p. 1. (Questions de sociologie, 1984).

CORNEJO POLAR, Antonio

1985

"Las literaturas marginales y la crítica: una propuesta" en Pukio, $\mathrm{N}^{\circ} 2$, Lima. 
ESPINORELUCÉ, Gonzalo

1999

1999
Imágenes de la inclusión andina. Literatura peruana del XIX. Lima, Universidad Nacional Mayor de San Marcos, Insti- tuto de Investigaciones Humanísticas.

La literatura oral o la literatura de tradición oral. Quito, Abyayala.

\section{FOLKLORE}

1946

Homenaje póstumo a Hildebrando Castro Pozo. Lima, Folklore $\mathrm{N}^{\circ}$ 16. [Trae textos de Amadeo Rivera, Nicanor de la Fuente y Luis E. Valcárcel; Florencio de la Sierra, José Varallanos, Juan María Merino y Erasmo Roca S.; y, José S. Warner, Pablo M. Uceda, Graciela de Urteaga y Anaximandro Vega].

GODENZZI, Juan Carlos

1994

1999

"Tradición oral andina: Problemas metodológicos del análisis del discurso" en América Indígena, Vol. 54. México, octubrediciembre; pp. 189-208. Tradición oral andina y amazónica; pp. 273-290.

Tradición bial tandina GuamazónicasMétodos de análisis e interpretacióripdecteiros. Cusco2 Centro.Bartolomé de las Casas.

GONZÁLEZPRADA, Manuel

1985

1904 "Discurso en el Politeama" (1888) en Pájinas libres. Prólogo y notas de Luis Alberto Sánchez, Lima, Ed. COPE, 1985; pp. 86-92.

"Nuestros indios" en Horas de lucha. 2a. ed. Callao, Tip. Lux, 1924; pp. 311-338. Manuel Gonzalez Prada, Antología. Paginas libertarias, comp. de Hugo García Salvattecci (Lima, Biblioteca Peruana, 1975) pp. 111-132.

GRAMSCI, Antonio 1981 Antología. Selección, traducción y notas de Manuel Sacristán. 6a. ed. México, Siglo Veintiuno Editores. 
HOWARD-MALVERDE, Rosaleen

The Speakin of History: "Willapaakushayki" or Quechua Ways of Telling the Past. London: Univesity of London, Institute of Latin American Studies.

MANNHEIM, Bruce

1987

"Couplets and oblique contexts: The social organization of a folksong"'en Text, Vol. 7, N. ${ }^{\circ} 3$. Amsterdam, 1987; pp. 265-288.

1986:

"Popular son and popular grammar, poetry and metalangue" en Word, vol. 37, N. 1-2. April-august 1986: 45-75.

MANNHEIM, Bruce $y$ Krista van VLEET

"The Dialogics of Souther Quechua Narrative" en American Anthropolo-gist 100 (2) 326-346.

MARCONE, Jorge

1997

La oralidad escrita. Sobre la reivindicación y re-inscripción del discurso oral. Lima, Pontificia Universidad Católica del Perú, Fondo Editorial.

PALMA, Clemente

\section{Biblioteca de Letras}

1879

"El Porvenir de las razas" en Fin de Siglo Retrato de Hispanoamérica en la época modernista de Robert Jay Glickman (Toronto, Canadian Academy of the Arts, 1999), pp. 229-231.

VARGAS LLOSA, Mario

1958

"Hildebrando Castro Pozo". Cultura Peruana, $\mathrm{N}^{\circ} 11$, mayo, pp. $[13,68], N^{\circ} 12$, junio, pp. $[13,55] ; N^{\circ} 13$, julio, pp. $[15,59]$. 